\title{
Awareness of Cervical Cancer, Papanicolaou's Smear and Its Utilisation among Female Undergraduates in Ibadan
}

\author{
$O A$ Ayinde $^{\prime}$, AO Omigbodun ${ }^{\prime}$ and AO Ilesanmi ${ }^{\prime}$
}

\begin{abstract}
A survey was conducted among 421 undergraduates of the University of Ibadan using self-administered questionnaires probing into their risk factors for neoplastic cervical lesions, awareness of cervical cancer, Papanicolaou's smear and its utilisation. The percentage of sexually active respondents was $81.5 \%$. Sexual exposure before the age of 20 years occurred in $51.7 \%$. The mean age at sexual debut was 18.8 years while the modal age was 18 years. Fifty seven per cent had multiple sexual partners, but only $38.1 \%$ used condoms. Seventy one per cent were aware of cervical cancer, while only 33.5\% were aware of Papanicolaou's smear. Awareness was found to be more among medical students and the married ones. On the other hand, only $8.3 \%$ of them had ever done a Papanicolaou's smear. There is a need to increase awareness and incorporate cervical screening into the preexisting university health services. Also, logistic barriers to cervical screening need to be removed. (Afr J Reprod Health 2004; 8[3]:68-80)
\end{abstract}

\section{RÉSUMÉ}

La conscience du cancer du col, du test de papanicolaou et son utilisation chez les étudiantes universitaires à Ibadan. Une enquête a été menée auprès des 421 étudiants de l'université d'Ibadan à l'aide des questionnaires autoadministrés qui exploraient leurs facteurs de risque pour les lésions du col néoplastiques, la conscience du cancer du col, le test de Papanicolaou et son utilisation. Le pourcentage des interviewées qui étaient sexuellement actives était de 81,5\%. Celles qui étaient exposées à l'acte sexuel avant l'âge de 20 ans constituaient $51.7 \%$. L'âge moyen lors du premier acte sexuel était 18,8 ans alors que l'âge modal était 18 ans. Cinquante-sept avaient des partenaires multiples, mais seuls $38,1 \%$ utilisaient des préservatifs. Soixante et onze étaient conscientes du cancer du col tandis que seuls 33.5\% étaient conscientes du test de Papanicolaou. Il s'était trouvé qu'il y avait plus de conscience chez les étudiantes en médecine et les étudiantes mariées. Par contre, seuls $8.3 \%$ parmi elles avaient subi le test Papanicolaou. Il y a le besoin d'augmenter la sensibilisation et d'incorporer le dépistage du cancer du col dans le service de santé universitaire pré-existent. Il faut également enlever les obstacles au dépistage du cancer du col. (Rev Afr Santé Reprod2004; 8[3]:68-80)

KEY WORDS: Cervical cancer, sexuality, Papanicolaou's smear, undergraduates

${ }^{1}$ Department of Obstetrics and Gynaecology, University College Hospital, Ibadan, Nigeria.

Correspondence: $\operatorname{Dr}$ O. A. Ayinde, Department of Obstetrics and Gynaecology,

University College Hospital, Ibadan, Nigeria. Tel: 23422410088 Ext. 3727; E-mail: sola_ayinde@yahoo.com 


\section{Introduction}

Carcinoma of the cervix is a major public health problem throughout the world. It is the second most common malignancy in women worldwide. However, it is the most common cancer in women in the third world, where over three quarters of the estimated half a million newly diagnosed cases occur annually. ${ }^{1,2}$ Apart from the burden in terms of number borne by this part of the world, other peculiar negative trends observed are lower mean age of diagnosis, late presentation and resultant very low five-year survival data. ${ }^{3,4} \mathrm{In}$ developing countries, cervical cancer tends to present about 15 years earlier than it does in developed countries. It is therefore postulated that a more aggressive variant of the disease probably occurs in this environment. ${ }^{5}$ As many as $80 \%$ of diagnosed cases are detected in the advanced stages in which treatment, even when available, has a markedly reduced likelihood of success. ${ }^{6}$ Many cases remain undiagnosed. WHO estimates that the contribution of cervical cancer to adult female death is $35 \%$.

Evidence from epidemiological studies coupled with recent advanced molecular biology findings have established a strong causal association between infection by certain serotypes (particularly 16 and 18) of sexually transmitted human papilloma virus (HPV) and cervical cancer. The virus exerts greater effects during periods of rapid metaplasia in the cervical epithelium, mostly in the period of adolescence. ${ }^{8}$ Therefore, certain sexual behaviours are known to predispose to cancer of the cervix. These are early sexual debut (earlier than the age of 20 years) and sexual promiscuity, either in the female or her partner. The number of sexual partners is the major independent risk factor whereas age at first sexual intercourse is a confounder. ${ }^{9,10}$ Others are high parity and low socio-economic status. These factors are prevalent in Nigeria and other developing countries. ${ }^{10}$ Though earlier studies were suggestive of the protective effect of barrier contraceptives, condom use has been shown to be only partially protective against HPV infection, unlike other sexually transmitted diseases.

In Nigeria, the lower age limit for admission into most tertiary institutions is 16 years. Therefore, many undergraduates will be in their late teens and early twenties. ${ }^{12}$ As a result of the risk-taking behaviour of people in this age group, they are thought to be at increased risks of sexually transmitted diseases and possibly cervical cancer later in life. ${ }^{12,13}$ Some reasons that have been adduced for this include the fact that most of the undergraduates live away from home in school hostels, thereby weakening parental control and supervision. They become exposed to influences that encourage casual sexual relationship and have to take important decisions about their social and reproductive lives. ${ }^{12}$ Many of them experiment with unprotected sex and multiple sexual partners as a result of intense peer influence. The prevalence of dysplastic cervical lesions as high as $29 \%$ was found in a study of sexually active adolescents in the United States. ${ }^{12}$ This is similar to what obtains in adults, though most are of the low-grade type. ${ }^{14}$ However, there is paucity of such data in this environment because many cervical screening programmes remain unfriendly to this category of people.

Availability of simple screening tests for detecting treatable pre-invasive and early invasive lesions, particularly periodic Papanicolaou's smear, makes the disease amenable to prevention and cure at the early stages of its evolution. ${ }^{15}$ This screening modality has been shown to have significantly reduced the mortality associated the condition. ${ }^{15}$ It is therefore recommended for all sexually active females. ${ }^{4}$ 
Although there has been increased public interest in health promotion, early detection and preventive health care for adolescents and young people, yet there are significant barriers to accessing the health care system. ${ }^{16}$ These include spatial accessibility, lack of reproductive health education among youths and stigmatisation by health workers. ${ }^{17}$ Therefore, it is imperative to provide quality professional development for health professionals in adolescent health care. ${ }^{16}$ Siahpush and Singh observed certain socio-demographic factors associated with underutilisation of cervical cancer screening. These are ages under 30 and over 49 years and being unmarried. ${ }^{18}$ Most female undergraduates are under 30 years of age. ${ }^{11}$ The study suggests that as part of a comprehensive cancer screening strategy, women who are unlikely to obtain a Pap smear might benefit from targeted interventions to improve adherence to cervical cancer screening programmes. $\mathrm{T}$ h e major sources of information about various reproductive health matters and programmes among young people include relations and friends, school, health facilities, mass media, public lecture, among others. In recent times, however, the use of the internet is becoming increasingly popular among Nigerian undergraduates and young people in general. Goold et al observed that the internet could be a practical and accessible way of delivering sexual health education to young people, particularly if it is incorporated into websites they enjoy.

The majority of cervical cancer cases seen in this environment occur between 35 and 65 years of age and it takes about 10-15 years for progression to invasive disease to occur. ${ }^{20}$ Therefore, many of the patients that developed cancer of the cervix would have had pre-invasive lesions as early as the age of 20-25 years. Many undergraduates fall into this age category. ${ }^{11}$ This study therefore attempts to provide useful information on the prevalence of high-risk sexual behaviours known to favour the development of neoplastic cervical lesions later in life among various categories of female undergraduates. It also assesses their awareness about the disease and its prevention.

\section{Materials and Methods}

This cross-sectional study was conducted among female undergraduates of the University of Ibadan. The survey instrument was a questionnaire containing closed-ended questions on respondent's biodata, sexual history, awareness about cervical cancer and screening practices. Pre-testing of the questionnaire was done among 20 students before the final questionnaire was developed. The calculated minimum sample size was 386 , using the formula by Kish, ${ }^{21,22}$ based on 95\% confidence interval and assuming the awareness of pap smear of $50 \%$, as no data from previous studies among a similar population was available. Twenty five per cent over-sampling was done to allow for incomplete responses. Hence, a sample size of 480 was used. The questionnaire was administered to a random sample of 480 students from the three female hostels in the university in 2002. Each room had four occupants. Therefore, a total of 120 rooms were needed for sampling, but 130 random room numbers were generated using the 'epitable' of the EPI INFO version 2000 (Centre for Disease Control, Atlanta, Georgia) to make up for non-response by some members of the selected rooms.

Respondents were recruited from the hostels by fellow female undergraduates, who were trained for the purpose. This involved prior provision of an information leaflet stating the protocol for the study in clear 
terms. Thereafter, willing respondents completed the consent form before they were given the self-administered questionnaires. In cases where there was apparent lack of knowledge about cervical cancer or Pap smear, attempts were made to explain what the condition or procedure was by the interviewer. Data obtained were entered into a computer using EPI INFO 2000 software. Initial analysis was by generation of frequency tables while further analysis involved crosstabulations to explore statistical relationships between variables. The observed differences were subjected to chi square test and the level of statistical significance was set at $\mathrm{p}<0.05$. Graphs and figures were drawn using the Microsoft Excel software.

\section{Results}

Demographic Characteristics

Four hundred and eighty three respondents completed the questionnaire; 62 were incompletely filled, leaving $421(87.2 \%)$ as the total number of analysable questionnaires.

The age of respondents ranged from 16 to 36 years. Their mean age was 23.6 years $( \pm 3.6)$ and the modal age was 22 years. Table 1 shows the distribution of respondents based on their demographic characteristics and sexual activity. Three hundred and eleven (73.9\%) were 25 years old and below. They were distributed across the College of Medicine and seven other faculties in the university, but the College of Medicine had more respondents $(23.6 \%)$ than others. Majority (98.6\%) of the students were in their first to fourth year of study. Only $1.4 \%$ was in year 5 . Three hundred and forty eight $(82.7 \%)$ were single while the remaining $17.5 \%$ were married. Christians constituted 72.0\%, 27.3\% were Muslims, while only $0.7 \%$ belonged to other religions. The majority (67.2\%) of respondents were Yoruba, $13.8 \%$ were Igbo, $5.7 \%$ were Hausa, while $13.3 \%$ belonged to other ethnic groups such as Edo, Efik, Urhobo, etc.

\section{Sexual Activity}

Three hundred and forty three $(81.5 \%)$ of the respondents were sexually active, their modal age at first sexual intercourse was 18 years. Two hundred and eighteen $(51.7 \%$ of the respondents) of the sexually active respondents had been exposed before the age of 20 years. Their ages at sexual debut ranged from 11 to 27 years. Their mean age was 18.8 years $( \pm 2.7)$ while their modal age was 18 years. This is illustrated in figure 1 .

Two hundred and forty $(70.0 \%)$ of the 343 sexually active students (or $57.0 \%$ of the total respondents) had multiple sexual partners. Sixty three (18.5\%) had had four or more sexual partners. Two hundred and fifty five $(74.3 \%)$ had been pregnant at one time or the other. Only $131(38.1 \%)$ of the sexually active respondents were using condoms during coitus.

\section{Awareness}

Three hundred and eighty two $(90.7 \%)$ of the respondents were aware of cancer. However, $299(71.0 \%)$ were aware of cervical cancer. The distribution of respondents based on their awareness of cervical cancer and Papanicolaou's smear is shown in Table 2. Ninety six per cent of students of the College of Medicine were aware of cervical cancer, compared to $63.7 \%$ of students from other colleges. Among married respondents $94.5 \%$ were aware of the disease, while $66.4 \%$ of the singles were aware. Also, $75.8 \%$ of sexually 
Table 1 Demographic Characteristics and Sexual Activity of the Study Population

\begin{tabular}{|c|c|c|c|c|c|c|}
\hline \multirow[b]{2}{*}{ Characteristics } & \multirow[b]{2}{*}{ Number (\%) } & \multicolumn{4}{|c|}{ Number of sexual partners } & \multirow[b]{2}{*}{$\geq 4$} \\
\hline & & $\mathbf{0}$ & 1 & 2 & 3 & \\
\hline \multicolumn{7}{|l|}{ Age (years) } \\
\hline$<20$ & $51(12.1)$ & 42 & 4 & 2 & 2 & 1 \\
\hline $20-25$ & $260(61.8)$ & 36 & 69 & 88 & 29 & 29 \\
\hline $26-30$ & $90(21.4)$ & 0 & 19 & 29 & 28 & 28 \\
\hline$>30$ & $20(4.8)$ & 0 & 10 & 1 & 6 & 6 \\
\hline \multicolumn{7}{|l|}{ Faculty } \\
\hline Agriculture & $25(6.0)$ & 11 & 3 & 10 & 1 & 0 \\
\hline Education & $42(10.0)$ & 1 & 9 & 21 & 2 & 9 \\
\hline Engineering & $29(6.9)$ & 6 & 3 & 12 & 3 & 5 \\
\hline Arts & $51(12.1)$ & 13 & 10 & 21 & 3 & 4 \\
\hline Law & $44(10.5)$ & 3 & 6 & 10 & 16 & 9 \\
\hline Medicine & 99 (23.6) & 18 & 28 & 20 & 25 & 8 \\
\hline Sciences & 83 (19.6) & 25 & 26 & 23 & 5 & 4 \\
\hline Social science & $48(11.5)$ & 0 & 17 & 3 & 2 & 26 \\
\hline \multicolumn{7}{|l|}{ Marital status } \\
\hline Single & 348 (82.7) & 76 & 68 & 103 & 46 & 55 \\
\hline Married & 73 (17.3) & 2 & 34 & 17 & 11 & 9 \\
\hline \multicolumn{7}{|l|}{ Religion } \\
\hline Christianity & $303(72.0)$ & 60 & 79 & 78 & 28 & 58 \\
\hline Islam & $114(27.3)$ & 18 & 23 & 41 & 27 & 5 \\
\hline Others & $4(0.7)$ & 0 & 0 & 1 & 2 & 1 \\
\hline \multicolumn{7}{|l|}{ Tribe } \\
\hline Hausa & $24(5.7)$ & 4 & 13 & 2 & 5 & 0 \\
\hline Igbo & $58(13.8)$ & 10 & 16 & 9 & 12 & 11 \\
\hline Yoruba & $283(67.2)$ & 51 & 56 & 10 & 35 & 40 \\
\hline Others & $56(13.3)$ & 13 & 17 & 8 & 5 & 13 \\
\hline Total & 421 & 78 & 102 & 120 & 57 & 64 \\
\hline
\end{tabular}


Table 2 Awareness of Cervical Cancer and Papanicolaou's Smear among Respondents

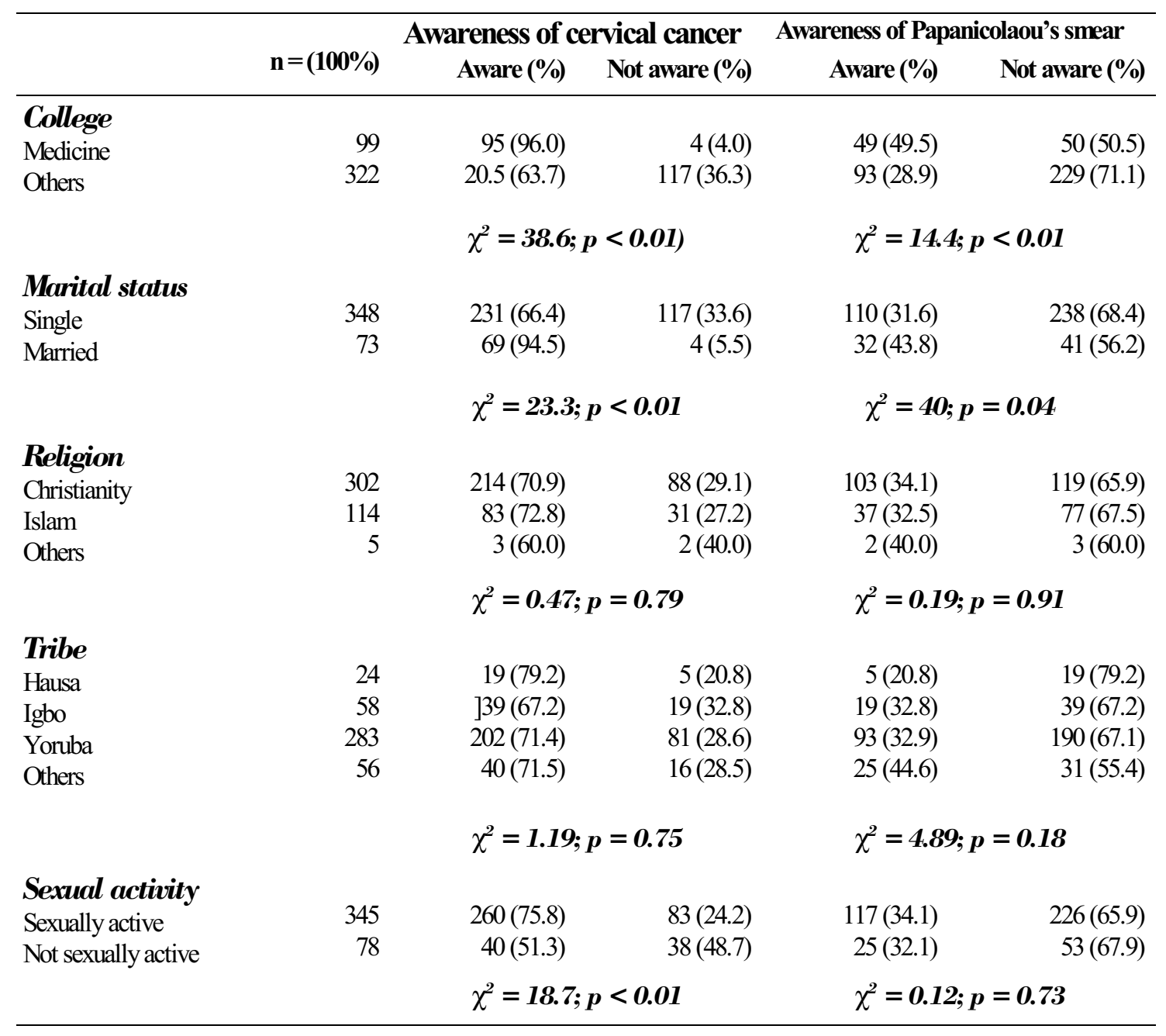


Active students were aware of the disease, compared to $51.3 \%$ of the non-sexually active. Proportions of respondents who were aware of the tumour were similar among the religious groups (60.0 to $72.8 \%)$ and tribes (67.2 to $79.2 \%$ ). Table 3 shows that 118 (39.5\%) became aware through hospital visits, while $91(30.4 \%)$ became aware through the mass media. Other means of awareness were friends, colleagues and relations (8.0\%) and the internet (7.4\%).

In contrast, only $141(33.5 \%)$ were aware of Papanicolaou's smear. The remaining $280(66.5 \%)$ had never heard of the test (Table 2). Of the College of Medicine students, $49.5 \%$ were aware of Papanicolaou's smear, compared to $28.9 \%$ of students from other colleges and faculties. Also, $43.8 \%$ of married respondents, compared to $31.6 \%$ of singles, were aware of the test. Comparable percentages of students had knowledge of Pap smear across the religions, tribes and sexual activity. The majority (91 or 64.3\%) of the former group became aware through hospital visits. Twenty one (15.4\%) knew through the mass media, 18 (12.6\%) through friends/colleagues/relatives, 2 (1.4\%) through the internet and $3(2.1 \%)$ through other means such as books (Table 4).

Of the 142 respondents that were aware of Pap smear, 105 (73.9\%) had correct knowledge of the use of Pap smear as a screening test for cervical cancer and its precursors. Also, 91 respondents $(64.1 \%)$ had correct knowledge of those who should have Pap smear, i.e., all sexually active females. Others thought that the test is reserved for women who have started childbearing or elderly women. Of those who were aware of Pap smear $95.8 \%$ and $76 \%$ of students of the College of Medicine and other faculties/colleges respectively knew the correct use of the test. However, level of knowledge about correct use of the test was comparable across marital status, religion, tribe and sexual activities.

\section{Table 3 Source of Information on Cervical Cancer and Papanicolaou's Smear among Respondents}

\begin{tabular}{|l|r|r|}
\hline Source & $\begin{array}{r}\text { Number of respondents aware of } \\
\text { cervical cancer (\%) }\end{array}$ & $\begin{array}{r}\text { Number of respondents } \\
\text { aware of Pap smear (\%) }\end{array}$ \\
\hline Friends/colleagues/relations & $24(8.0)$ & $6(4.2)$ \\
Hospital & $118(39.5)$ & $92(64.3)$ \\
Internet & $22(7.4)$ & $2(2.0)$ \\
Mass media & $91(30.4)$ & $21(15.4)$ \\
Public lecture & $44(14.7)$ & $18(12.6)$ \\
Others & $0(0.0)$ & $3(2.1)$ \\
& & $142(100.0 \%)$ \\
\hline Total & $299(100.0)$ & \\
\hline
\end{tabular}




\section{Utilisation of Papanicolaou's Smear}

Table 4 shows the distribution of respondents based on previous utilisation of Papanicolaou's smear across the various biosocial characteristics. Only $8.3 \%$ of all respondents have ever had a Pap smear done. The vast majority $(91.7 \%)$ had never had it. The rate of non-utilisation of the test was similar across the faculties/colleges (91.9\% among medical students, $91.6 \%$ among other students); religions $(92.4 \%$ among Christians, $89.5 \%$ among Muslims and $100 \%$ among others) and tribes (87.5\% among the Hausas, 82.6\% among the Igbos, 91.9\% among the Yorubas, and $91.1 \%$ among other tribes). However, non-utilisation rate among single respondents $(96.8 \%)$ was found to be much higher than among the married ones $(65.8 \%)\left(x^{2}=69.9 ; p<0.01\right)$.
Use rate also varied with the year of study; from $96.2 \%$ among first year students to $66.7 \%$ among fifth year students. Three hundred and eight $(89.8 \%)$ of the sexually active have never had the test while the entire sexually unexposed have never had it. Various reasons were given for not having the test done; $64.1 \%$ cited lack of awareness about the test, $16.0 \%$ did not know where to have the test, $5.9 \%$ because of the cost, while $9.5 \%$ were just reluctant to have the test. Out of the 386 who have never had Pap smear, 68\% were willing to have it in future while the remaining $32 \%$ were not willing even if safety of the test is guaranteed and the cost taken care of. Reasons for this included belief in not being at risk of cancer of the cervix $(52.3 \%)$, belief that the test is not useful (34.2\%), feeling that the test is cumbersome (7.2\%),

Table 4 Utilisation of Pap Smear among Respondents

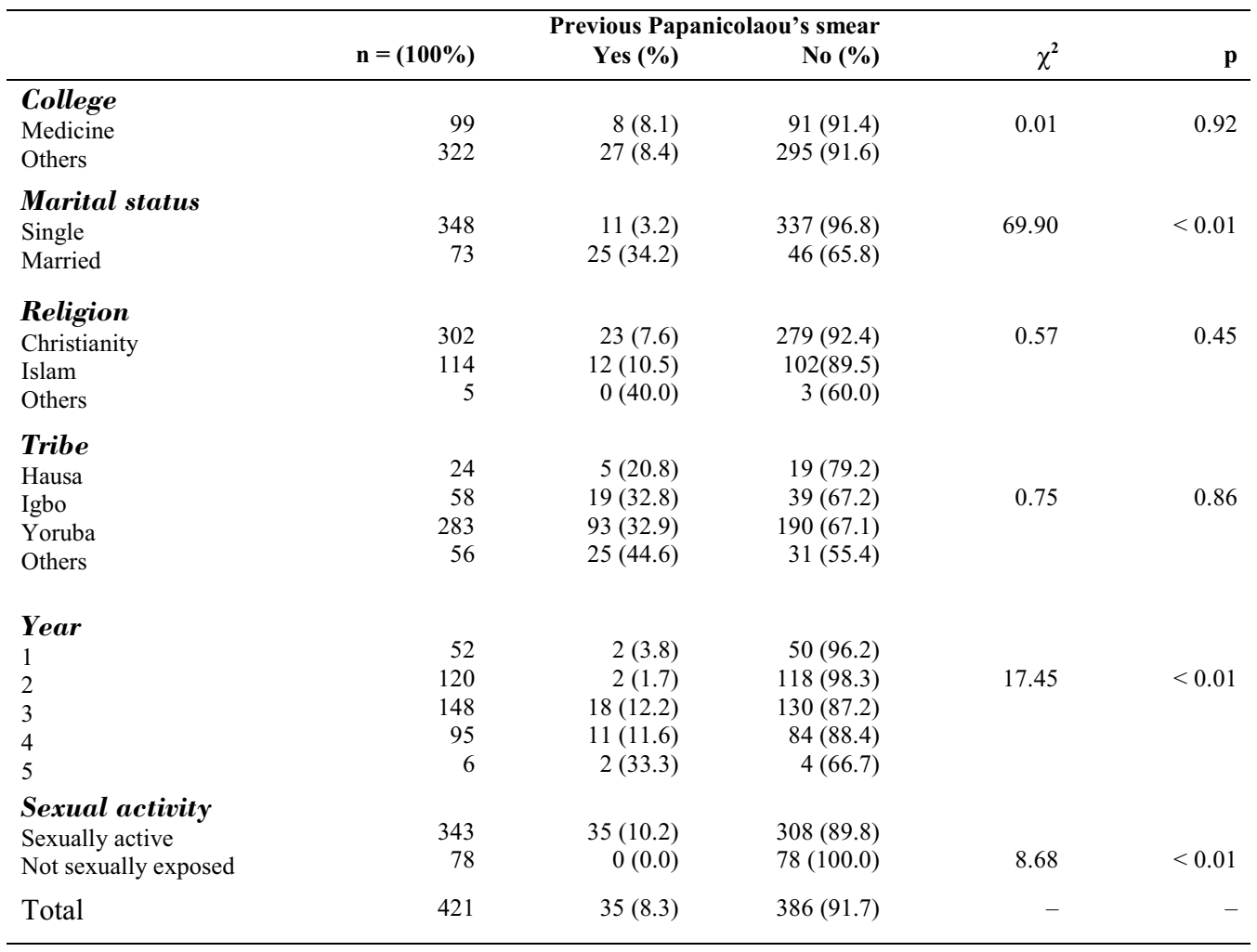




\section{Figure 1 Distribution of Respondents' Age at First Sexual Exposure}

\section{Discussion}

The lower age limit for admission into most Nigerian universities is 16 years. Therefore, most undergraduates are in their late teens and early twenties. A majority (73.9\%) of the study population were aged 25 years and below. This was similar to findings by Arowojolu et al among a similar population. ${ }^{11}$ It has been observed that the risk of developing cervical cancer is high for most women in the third world due to peculiar socio-economic characteristics including poverty and illiteracy (which reduce the power of women to bargain in sexual matters). Others are low prevalence of condom use, high parity and poor utilisation of screening facilities. ${ }^{8,10}$ This study shows that the risk factors for developing the disease are also prevalent among undergraduates.
Majority $(81.5 \%)$ of the study population were sexually active. Many of them also had early sexual debut. Over half of them $(51.7 \%)$ had their first sexual exposure before the age of 20 years. Apart from this, having multiple sexual partners was a common finding; $70 \%$ of the sexually active. The pattern of sexual behaviour seen in this study is similar to what was found in previous studies. ${ }^{11,20}$ The partial protective effect of condom use against infection by the main aetiological agent, human papilloma virus (HPV), is well-documented. ${ }^{13}$ The use of condoms was however found to be unpopular among the undergraduates. Only $38.1 \%$ of the population studied were using condoms. A similar low rate of condom utilisation was reported by Unuigbe and Ogbeide in a study on sexual practices among adolescents in 
Benin City, Nigeria. ${ }^{23}$ All the aforementioned factors would make the average female undergraduate at considerable risk of contracting HPV infection.

Awareness of cervical cancer was high but needs to be improved, considering how common the disease is in developing countries. About $71 \%$ of the respondents had knowledge of the tumour. However, the factors that were in favour of knowing about the disease included being a student of the College of Medicine, marriage and sexual activity (Table 2). The religion and tribe of respondents had no statistically significant effect on knowledge about the disease. On the other hand, awareness about Papanicolaou's smear was generally poor, as only $33.5 \%$ of the students knew about the test. The determinants of awareness were, being a student of the College of Medicine and marriage. This is possibly explained by the fact that the commonest means of awareness about cervical cancer and Papanicolaou's smear was contact with the hospital. This is only followed by the mass media (Table 3). Married women often visit the hospital when they are pregnant. The majority of those who were aware of the test knew its correct use (73.9\%) and in whom it is indicated (64.1\%). The only factor identified to be associated with correct knowledge was being a student of the College of Medicine. This is expected, as the medical students are more likely to have come across information on the disease and its prevention in the course of their training. This is in line with the findings of Lindau et al, which suggested that health literacy is a better predictor of cervical cancer screening knowledge than formal education or ethnicity. ${ }^{24}$
Another major finding of the study is that awareness of Papanicolaou's smear far outweighed its utilisation by the undergraduates. Only $8.3 \%$ had ever had a Pap smear before. It was however observed that the married, the sexually active and students in the third year and above were more likely to have the test were (Table 4). In an Australian study, it was similarly observed that single women and those under the age of 30 years are at greater risks of not having knowledge of Papanicolaou's smear and not utilising it. ${ }^{18}$ The high rate of non-utilisation of the test is not surprising, as previous surveys carried out among female health professionals working in hospitals where facilities for the test are available showed similar negative attitude towards having it. . $^{25,26}$ The most frequent reason for not having Pap smear was lack of awareness about the test $(64.1 \%)$. Less frequent reasons were lack of knowledge of centres where the test could be done $(16.0 \%)$, reluctance $(9.5 \%)$ and cost (5.9\%). Among health workers, a relatively older population, the major reason was reluctance. ${ }^{25}$ This reason, which was also given by some of the students, was probably due to anxiety regarding physical privacy as observed by Watkins et al. ${ }^{27}$ Health education appears to have a prominent role to play in increasing awareness and addressing some of the negative biases the students have against the test. This is important as all those who claimed that they never wish to have the test done had erroneous beliefs. Most of them simply believed in not being prone to cervical cancer or that the test is either cumbersome or not useful at all. 
There is increasing emphasis on the need for youths to be involved in planning, implementing and evaluating programmes that have direct impact on their daily lives. ${ }^{28}$ Therefore, youths should be encouraged to play more active roles in reproductive health matters through provision of information, education and counselling (IEC) services. Access to such services should be strictly private and confidential. Also, awareness campaign should be intensified through the popular means identified among the students and other young people. The major means identified by this study are hospital visits, mass media and public lecture. Since some respondents became aware of cervical cancer and Papanicolaou's smear through the internet, and with increasing access by more undergraduates to the internet, service providers can be encouraged to promote cervical cancer awareness and prevention by incorporating relevant information into popular websites visited by students. ${ }^{20}$

\section{Conclusion and Recommendations}

This study shows that the risk factors for neoplastic cervical lesions are prevalent among female undergraduates. Though awareness about cervical cancer was fairly high, this needs to be improved upon considering the burden of the disease in developing countries. Knowledge of Papanicolaou's smear, its use and indication were generally poor and the procedure itself was found to be unpopular among the students. Students of the College of Medicine and married women tend to be better informed possibly because they are more likely to attend health facilities, the commonest source of information in this study.
It is therefore recommended that reproductive health education about cervical cancer, sexually transmitted diseases and their prevention should be intensified in our high schools and higher institutions. Knowledge of risk factors and the need for regular cervical screening should be emphasised. Family and sex life education should be introduced into the school curriculum. In the universities, it may be worthwhile to introduce reproductive health as a compulsory general studies course for both males and females. The mass media and the increasingly popular internet need to be put to better use as potent means of enlightenment. Information on cervical cancer and its prevention could be linked to those websites that are popular among students and young people. As students represent the enlightened future of the country, their awareness of the risk factors for cervical cancer could go a long way in making primary prevention of the condition more effective on the long run. These young people should also be encouraged to increase the age at first coitus, minimise the number of sexual partners and embrace the use of condoms.

The existing logistics involved in obtaining a Pap smear is too cumbersome and discouraging. Therefore, it will be desirable to integrate cervical screening programmes and other reproductive health services into the university health service delivery. Also, in other centres where reproductive health services are rendered, they should be youthfriendly in nature. For instance, greater access to screening can be facilitated by establishing 'walk-in' clinics. With these, women for routine Pap smear will not be made to pass through the usual protocols of a routine gynaecological clinic, as this has been 
identified as a possible cause of fear of invasion of privacy and reluctance towards cervical screening.

The issue of cost of screening cannot be over-emphasised, as this may put it beyond the reach of undergraduates, who are mostly dependent. Attempts should be made to address this issue by government and nongovernmental organisations through subsidisation.

\section{REFERENCES}

1. Schoell WM, Janicek MF and Mirhacheni R. Epidemiology and biology of cervical cancer. Sem Surg Oncol 1999; 16:203-211.

2. Babarinsa IA, Akang EEU and Adewole IF. Pattern of gynaecological malignancies at Ibadan cancer registry (1976-1995). Nig Quart J Med 1998; 8: 103-106.

3. Edozien LC and Adewole IF. Cervical carcinoma in Nigeria a need for early detection. Afr J Med Med Sci 1993; 22: 87-92.

4. Omigbodun AO and Akanmu TI. Clinicopathologic correlates of deasease stages in Nigerian cervical cancer patients. J Obstet Gynaecol C Afr 1991; 9: $79-81$

5. Ekanem E and Abidoye R. Some epidemological and clinical features of cervical cancer in Lagos, Nigeria. Public Health 1987; 101: 123-128.

6. Luthra UK, Ray $M$ and Sehgal A. Clinical downstaging of uterine cervix by paramedical personnel. Lancet 1988; 1: 1401 .
7. WHO. Control of cancer of the cervix uteri. BullWHO 1986; 64: 607-618.

8. Bosch FX, Munoz $\mathrm{N}$ and de Sanjose S. Human paplilloma virus and other risk factors for cervical cancer. Biomed Pharmacoth1997; 51:268-275.

9. Stanley K, Stjernsward J a n d Koroltchouk V. Women and cancer. World Health Stat Quart 1987; 267-278.

10. Olukoya AA. Cancer of the breast and cervix in Nigerian women and the role of primary health care. Nig Med Pract 1989; 18(2):26-30.

11. Arowojolu AO, Ilesanmi AO, Roberts OA and Okunlola MA. Sexuality, contraceptive choice and AIDS a w a reness a mong $\mathrm{Nigerian}$ undergraduates. Afr J Reprod Health 2002; 6(2): 60-70.

12. World Health Organisation. Exploring adolescent reproductive health. Research on Reproductive Health at WHO; Biennial Report2000, 2001,2002,43-45.

13. Cothran MM and White JP. Adolescent behaviour and sexually tansmitted diseases. Health Care Women Int 2002; 23(3): 306-319.

14. Simsir A, Brooks S, Cochran L, B ourquin P and Ioffe O B. Cervicovaginal abnormalities in sexually active adolescents. Implications for management. Acta Cytol 2002; 46(2): 271-276.

15. Guidozzi F. Screening for cervical cancer. Obstet Gynecol Survey 1996; 51(4): 247-252. 
16. Sanci L, Glover S and Coffey C. Adolescent health education programmes: theoretical principles in design and delivery. Ann Acad Med Singapore 2003; 32(1): 78-85.

17. Mashamba A and Robson E. Youth reproductive health services in Bulawayo, Zimbabwe. Health Place 2002; 8(4): 273-283.

18. Siahpush M and Singh GK. Sociodemographic predictors of pap test receipt, currency and knowledge among Australian women. Prev Med 2002; 35(4): 362-368.

19. Goold PC, Ward M and Carlin EM. Can the Internet be used to improve sexual health awareness in web-wise young people? I Fam Plann Reprod Health Care 2003;29(1):28-30.

20. Agency for Health Care Policy and Research. Evaluation of cervical cytology: evidence report/ technology assessment. No. 5, Rockville, 1999.

21. Kish L. Survey Sampling. New York: John Wiley and Sons, 20, 1965.

22. Kirkwood BR. Calculation of required sample size. In: Essentials of Medical Statistics. Blackwell Scientific Publishers, 1988, 191-200.
23. Lindau ST, Tomori C, Lyons T, Langseth L, Bennett CL and Garcia P. The association of health literacy with cervical cancer prevention. Knowledge and health behaviours in a multiethnic cohort of women. Am J Obstet Gynecol 2002; 186(5): 938-943.

24. Unuigbe IE and Ogbeide O. Sexual behaviour and perception of AIDS among adolescent girls in Benin City, Nigeria. Afr J Reprod Health 1999; 3(1): $39-44$.

25. Ayinde O.A., Omigbodun A.O. Knowledge, attitude and practices related to prevention of cancer of the cervix among female health workers in Ibadan. J Obstet Gynaecol 2003; 23(1): $55-58$.

26. Olaniyan OB, Agboghoroma OC and Ladipo OP. Knowledge and practice of cervical screening among female health workers in Government hospitals in Abuja metropolis, Nigeria. Trop J Obstet Gynaecol2000; 17(1): 18-20.

27. Watkins MM, Gabali C, Winkleby M, Gaona E and Lebaron S. Barriers to cervical cancer screening in rural Mexico. Int J Gynecol Cancer 2002; 12(5): 475-479.

28. Program of Action of the 1994 International Conference on Population and Development. Pop Dev Rev 1995; 21: 187-213. 